5th International EEIGM/AMASE/FORGEMAT Conference on Advanced Materials Research IOP Publishing IOP Conf. Series: Materials Science and Engineering 5 (2009) 012018 doi:10.1088/1757-899X/5/1/012018

\title{
Prediction of crack onset strain in composite laminates at mixed mode cracking
}

\author{
J Andersons ${ }^{1}$, E Spārniṇš ${ }^{1,2}$, R Joffe ${ }^{2}$ \\ ${ }^{1}$ Institute of Polymer Mechanics, University of Latvia, 23 Aizkraukles iela, LV-1006 \\ Rīga, Latvia \\ ${ }^{2}$ Division of Polymer Engineering, Luleå University of Technology, SE-971 87 Luleå, \\ Sweden \\ E-mail: janis.andersons@pmi.lv
}

\begin{abstract}
Failure process of continuous fiber reinforced composite laminates in tension usually starts with appearance of intralaminar cracks. In composite laminates with complex lay-ups and/or under combined loading, intralaminar cracks may develop in plies with different reinforcement directions. A necessary part of mixed mode cracking models is the criterion of failure. For propagation-controlled fracture it is usually formulated in terms of energy release rates and their critical values of the particular composite material. Intralaminar fracture toughness of unidirectionally reinforced glass/epoxy composite was experimentally determined at several mode I and mode II ratios. It is found that the crack propagation criterion, linear in terms of the energy release rates, reasonably well approximates the test results. The determined mixed mode cracking criterion was applied to predict intralaminar crack onset in cross-ply glass/epoxy composite under tensile loading. The predicted crack onset strain values agree with test results at small off-axes angles of the cracking ply (on-axis and $15^{\circ}$ off-axis loading), but underestimate crack onset at larger reinforcement angles with respect to the loading direction. The discrepancy is likely to be caused by the deviation of linearity in laminate response before cracking onset in these laminates, related to non-linear shear characteristics of unidirectional plies. The applicability of strength-based fracture criterion for initiation-controlled cracking is discussed.
\end{abstract}

\section{Introduction}

The first damage observed in a continuous fiber reinforced composite laminate in tension usually is intralaminar cracks along the fiber direction of unidirectionally reinforced (UD) laminae. The conditions of crack onset, progressive cracking, and the effect of intralaminar cracks on the reduced mechanical properties of laminates have been extensively studied experimentally and theoretically, see e.g. relatively recent reviews $[1,2]$.

The most frequently used laminate configuration in such studies has been cross-ply composite of lay-up $\left[0_{\mathrm{n}} / 90_{\mathrm{m}}\right]_{\mathrm{s}}$, subjected to tension along the $0^{\circ}$ direction, and developing cracks along fiber direction of the $90^{\circ}$ ply. It has been observed that the crack onset strain (COS) increases with reduction of the transverse ply thickness for relatively thin $90^{\circ}$ ply while remaining constant for relatively thick transverse ply [3-6].

The observed variation of COS with the cracking ply thickness in a cross-ply composite was explained in [4] invoking the concept of inherent flaws in the ply. Thin transverse plies are likely to 
5th International EEIGM/AMASE/FORGEMAT Conference on Advanced Materials Research IOP Publishing IOP Conf. Series: Materials Science and Engineering 5 (2009) $012018 \quad$ doi:10.1088/1757-899X/5/1/012018

contain flaws extending over the whole ply thickness $h$, therefore the energy release rate (ERR) available for flaw propagation in fiber direction should depend on $h$, hence thickness-dependent COS. By contrast, the flaws in a thick transverse ply are likely to be much smaller than $h$, therefore their ERR should be insensitive to ply thickness and the confinement characteristics, hence thicknessindependent COS equal or close to that of a UD composite under transverse tension [4].

Experimental studies of crack onset and growth in carbon [7] and glass [8] fiber reinforced crossply composites focused on initiation and propagation stages in crack development. The analyses suggest that cracking in thin plies is propagation controlled and thus governed by fracture mechanics whereas cracking of thick plies is initiation controlled and governed by ply strength. The transitional ply thickness is larger at greater intralaminar toughness [7]. Thus, in order for a transverse crack to appear, both initiation and propagation criteria should be met.

In composite laminates with complex lay-ups and/or under combined loading, intralaminar cracks may develop in plies with different reinforcement directions due to combined action of transverse tensile and in-plane shear stresses. Theoretical modeling performed in [4] predicts the same ply thickness dependence of cracking mechanism of the ply under complex loading as under pure tension. Some experimental observations also indirectly corroborate the presence of initiation and propagation governed stages in ply cracking under combined loading $[9,10]$.

In the present study, we derive COS of a cross-ply composite under off-axis tensile loading using strength and fracture mechanics criteria of failure of a UD ply. The theoretical prediction is compared with experimental results of glass/epoxy composite.

\section{Materials and tests}

The experimental data used in modeling are borrowed from [11] for UD glass/epoxy composite toughness, from $[12,13]$ for strength, and from [14] for crack onset strain of a UD lamina within a laminate in off-axis tension. For convenience and completeness, we concisely recapitulate material and test description below.

\subsection{UD composite}

As detailed in [11-13], UD plates of an E-glass/epoxy matrix composite were prepared by hand lay-up from a UD prepreg VICOTEX NVE 913/28\%/192/EC9756. The curing cycle comprised $30 \mathrm{~min}$ at $90^{\circ} \mathrm{C}$ followed by $60 \mathrm{~min}$ at $120^{\circ} \mathrm{C}$ under a 3 to 7 bar pressure. Rectangular specimens of 220 to 240 $\mathrm{mm}$ length and 22 to $26 \mathrm{~mm}$ width were cut from the plates under $20^{\circ}, 30^{\circ}, 45^{\circ}$, and $90^{\circ}$ angles to the ply reinforcement direction. The UD specimen thickness was about $1 \mathrm{~mm}$. The specimens were subjected to tension with stroke control at a loading rate of $2 \mathrm{~mm} / \mathrm{min}$ up to failure.

For toughness tests, a pre-crack was made in each composite specimen by, first, drilling a smalldiameter hole in the middle of the specimen and then sawing along the fibers in both directions from the hole for about $2.5 \mathrm{~mm}$ [11]. As a result, a pre-crack of about $5 \mathrm{~mm}$ length oriented in the fiber direction was obtained in the middle of each specimen. The specimens were tested up to failure with stroke control at $2 \mathrm{~mm} / \mathrm{min}$ rate. Specimens failed by unstable propagation of the pre-crack along the fiber direction.

\subsection{Cross-ply composite}

Cross-ply composite plates were prepared by hand lay-up from UD prepreg and cured. The prepreg material and cure cycle were the same as for UD specimen preparation described above. Rectangular specimens of 230 to $240 \mathrm{~mm}$ length and 21.5 to $22.5 \mathrm{~mm}$ width were cut from the plates at $0^{\circ}, 15^{\circ}, 30^{\circ}$, and $45^{\circ}$ angles with respect to the outer ply reinforcement direction, producing specimens of lay-ups $\left[02_{2} / 90_{2}\right]_{\mathrm{s}},\left[15_{2} /-75_{2}\right]_{\mathrm{s}},\left[30_{2} /-60_{2}\right]_{\mathrm{s}},\left[45_{2} /-45_{2}\right]_{\mathrm{s}}$. The specimen thickness was 0.82 to $0.88 \mathrm{~mm}$. A $100 \mathrm{~mm}$ long section of a specimen was inspected for the presence of intralaminar cracks during tension test. Due to the partial transparency of the material, cracks could be reliably observed in transmitted light. The cracks tended to originate at the free edges and to propagate parallel to the reinforcement direction of the cracking ply [14]. 
5th International EEIGM/AMASE/FORGEMAT Conference on Advanced Materials Research IOP Publishing IOP Conf. Series: Materials Science and Engineering 5 (2009) $012018 \quad$ doi:10.1088/1757-899X/5/1/012018

\section{Crack onset model}

We consider the conditions of transverse cracking onset in a UD ply of a composite laminate subjected to uniaxial tensile loading. The loading causes complex stress state in the confined ply that involves shear and transverse tensile stresses. The COS is derived by a strength-based criterion for crack initiation and a toughness-based criterion for crack propagation. The model can be easily generalized to combined loading of the laminate.

\subsection{Initiation-controlled cracking}

Crack initiation in a confined ply is determined by a combination of the transverse, $\sigma_{2}$, and shear, $\sigma_{12}$, stresses in the ply exceeding ply strength. Treating composite laminate as linear elastic, the ply stresses are linear functions of the applied tensile strain $\varepsilon$

$$
\sigma_{2}=\sigma_{2 r}+k_{2} \varepsilon \quad \sigma_{12}=k_{12} \varepsilon
$$

where $\sigma_{2 r}$ stands for the residual stress and the factors $k_{2}$ and $k_{12}$ are easily obtained by the classical laminate theory for each lay-up and ply considered. Ply strength under combined shear and tension transverse to the fibers can be described by a quadratic failure criterion (see e.g. [15, 16]):

$$
\left(\frac{\sigma_{2}}{\sigma_{2 c}}\right)^{2}+\left(\frac{\sigma_{12}}{\sigma_{12 c}}\right)^{2}=1
$$

where $\sigma_{2 c}$ and $\sigma_{12 c}$ designate, respectively, ply strength under tension transverse to the fibers and inplane shear. Combining (1) and (2), the criterion for onset of cracking in a given ply in a laminate is obtained. Neglecting residual stress, COS is given by

$$
\varepsilon=\left(\left(\frac{k_{2}}{\sigma_{2 c}}\right)^{2}+\left(\frac{k_{12}}{\sigma_{12 c}}\right)^{2}\right)^{-\frac{1}{2}}
$$

\subsection{Propagation-controlled cracking}

Consider a crack parallel to fiber direction of the UD ply, spanning whole ply thickness, and of sufficient length to attain steady-state level of ERR. The latter can be easily evaluated via crack face displacement at a given far-field stress, see e.g. [17]. Approximate analytical expressions for average crack face displacements of a crack in a ply located either in the middle or at the surface of a symmetric laminate have been derived under mode I [18] and mode II [19] conditions.

Based on $[17,18]$, mode I ERR for a transverse crack in a ply within a laminate is determined as

$$
G_{I}=\frac{h \bar{u}_{2} \sigma_{2}^{2}}{E_{2}}
$$

where $h$ is the transverse ply thickness, $\sigma_{2}$ designates, as above, the unperturbed stress in the ply, normal to the crack plane, the transverse Young's modulus of the UD ply is $E_{2}$, and $\bar{u}_{2}$ is the normalized average crack opening displacement as defined in [18]. The non-dimensional displacement is evaluated by an approximate relation, based on a series of FEM calculations, that has the following form $[17,18]$ : 
5th International EEIGM/AMASE/FORGEMAT Conference on Advanced Materials Research IOP Publishing IOP Conf. Series: Materials Science and Engineering 5 (2009) 012018 doi:10.1088/1757-899X/5/1/012018

$$
\bar{u}_{2}=A_{2}+B_{2}\left(\frac{E_{2}}{E_{s}}\right)^{n_{2}} .
$$

$E_{s}$ in (5) designates the in-plane Young's modulus of the sublaminate, confining the cracking ply, in direction normal to the crack plane. For a crack in the inner transverse layer of a symmetric composite laminate with equal inner ply and (total) sublaminate thicknesses, the parameters of (5) are as follows: $A_{2}=0.52, B_{2}=0.3075, n_{2}=0.671767$.

Similarly, mode II ERR for a transverse crack in a composite laminate is evaluated as

$$
G_{I I}=\frac{h \bar{u}_{1} \sigma_{12}^{2}}{G_{12}}
$$

where $\sigma_{12}$ stands for the unperturbed in-plane shear stress in the ply, in-plane shear modulus of the UD ply is $G_{12}$, and $\bar{u}_{1}$ is the normalized average sliding displacement of a crack face. An approximate relation for $\bar{u}_{1}$, similar to (5), is derived in [19]. For composite laminates with equal total thicknesses of the cracking ply and the confining sublaminates, it reduces to a constant. Specifically, $\bar{u}_{1}=0.42$ for a crack in the inner ply.

We assume a linear, in terms of the single-mode ERRs, crack propagation criterion under mixedmode loading:

$$
\frac{G_{I}}{G_{I c}}+\frac{G_{I I}}{G_{I I c}}=1
$$

with $G_{I c}, G_{I I c}$ designating the respective critical ERRs. The criterion is expressed in terms of ply stresses by inserting ERR expressions (4) and (6) into (7), resulting in:

$$
\frac{h \bar{u}_{2} \sigma_{2}^{2}}{E_{2} G_{I c}}+\frac{h \bar{u}_{1} \sigma_{12}^{2}}{G_{12} G_{I I c}}=1
$$

Finally, the applied strain at crack propagation is obtained, neglecting the residual stress, from (8), (1) as:

$$
\varepsilon=\left(\frac{h \bar{u}_{2} k_{2}^{2}}{E_{2} G_{I c}}+\frac{h \bar{u}_{1} k_{12}^{2}}{G_{12} G_{I I}}\right)^{-\frac{1}{2}}
$$

\section{Results and discussion}

In order to evaluate the agreement of prediction of the COS with experimental data [14] of cross-ply composite, the strength and toughness characteristics of a UD lamina have to be determined first. For strength, we use the off-axis tension test results [12]. The average strength of UD composite, $\sigma_{\varphi}$, as a function of the angle between loading axis and reinforcement direction $\varphi$ is shown in figure 1 . The theoretical estimate of $\sigma_{\varphi}$ is obtained by expressing the stresses in (2) via the applied stress at failure and solving (2) for the latter, with the result: 
5th International EEIGM/AMASE/FORGEMAT Conference on Advanced Materials Research IOP Publishing IOP Conf. Series: Materials Science and Engineering 5 (2009) 012018ｄoi:10.1088/1757-899X/5/1/012018

$$
\sigma_{\varphi}=\left(\left(\frac{\sin ^{2} \varphi}{\sigma_{2 c}}\right)^{2}+\left(\frac{\sin \varphi \cos \varphi}{\sigma_{12 c}}\right)^{2}\right)^{-\frac{1}{2}} .
$$

Transverse and shear strength estimates of the UD composite are obtained by fitting (10) to the test results as shown in figure 1 . This leads to $\sigma_{2 c}=58 \mathrm{MPa}$ and $\sigma_{12 c}=62 \mathrm{MPa}$.

For critical ERRs, we use the pre-cracked UD composite test results [11]. The average mode I and II ERRs at crack propagation, shown in figure 2, are derived from the respective stress intensity factors reported in [11]. It is seen in figure 2 that the crack propagation criterion (7) with $G_{I c}=300$ $\mathrm{J} / \mathrm{m}^{2}$ and $G_{\text {IIC }}=500 \mathrm{~J} / \mathrm{m}^{2}$ is in good agreement with the experimental data.

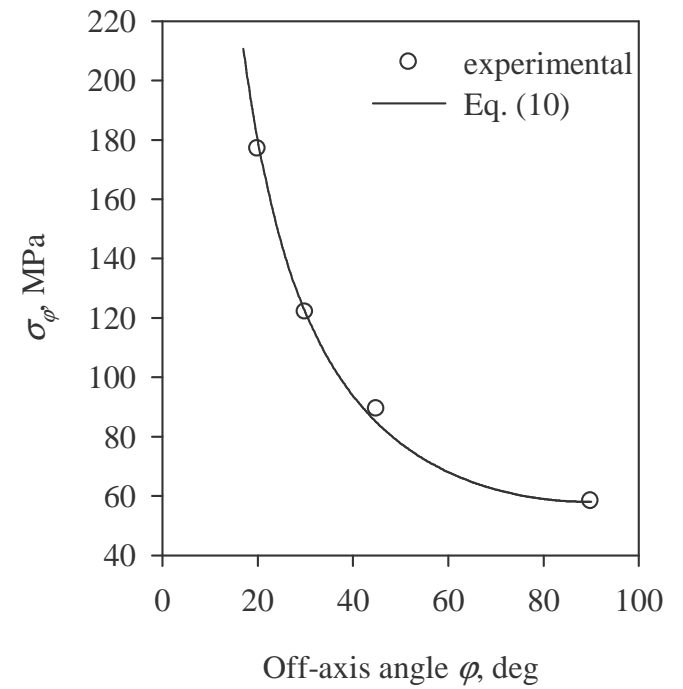

Figure 1. Tensile strength of UD glass/epoxy composite as a function of angle between reinforcement and loading directions.

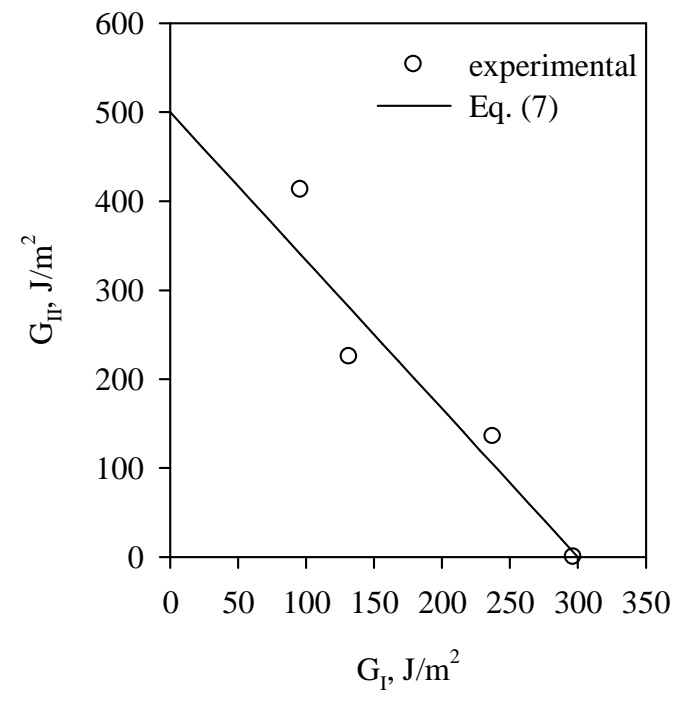

Figure 2. Mode I and II ERRs at the onset of crack propagation along fibers of UD glass/epoxy composite.

Having thus determined the parameters characterizing resistance of UD composite to crack initiation and propagation, we proceed with the analysis of cracking in a composite laminate. The experimental COSs of the inner ply of $\left[0_{2} / 90_{2}\right]_{s}$ cross-ply laminate under uniaxial tension at different angles $\alpha$ with respect to the reinforcement direction of the outer plies, derived form test results reported in [14], are shown in figure 3. It is seen that the crack initiation criterion (3) in the inner plies is met already at applied strain level considerably lower than the experimental COS. The actual appearance of mesoscopic cracks correlates reasonably well with the crack propagation criterion (9). This is in agreement with previous findings regarding COS under on-axis tension (i.e. pure mode I conditions), that COS of relatively thin transverse plies agrees with critical ERR criterion of fracture [3-6]. It is seen in figure 3 that the COS is underestimated by (9) for relatively large off-axis angles, $\alpha \geq 30^{\circ}$. This discrepancy is thought to be related to the non-linearity of laminate response seen in stress-strain diagrams for these laminates well before crack onset [14].

By contrast, in cross-ply composites with relatively thick transverse plies, subjected to on-axis tension, the crack propagation criterion is met at lower strains than the initiation criterion, and COS of intact laminates is determined by ply strength [3-6]. Circumstantial evidence suggests that the same holds true also for complex loading involving both transverse tensile and shear stresses in the cracking ply. In angle-ply laminates of lay-up $[0 / \varphi]_{\mathrm{s}}$ and relatively thick off-axis ply, the presence of notches substantially reduced COS [10] thus indicating that the COS of intact laminates is controlled by crack 
5th International EEIGM/AMASE/FORGEMAT Conference on Advanced Materials Research IOP Publishing IOP Conf. Series: Materials Science and Engineering 5 (2009) 012018 doi:10.1088/1757-899X/5/1/012018

initiation. Further, consider axial tension tests [9] of cylindrical specimens of lay-up $[ \pm \varphi]_{2}$ with $\varphi=$ $15,30,4560^{\circ}$ (manufactured by helical winding of epoxy-impregnated rowing on a cylindrical mandrel with subsequent curing and cutting). While the ultimate failure in tension of the angle-ply specimens was due to delamination, the limit of proportionality, corresponding to the onset of transverse cracking in the plies, agreed very well with the UD ply failure criterion (2) for all the reinforcement angles studied.

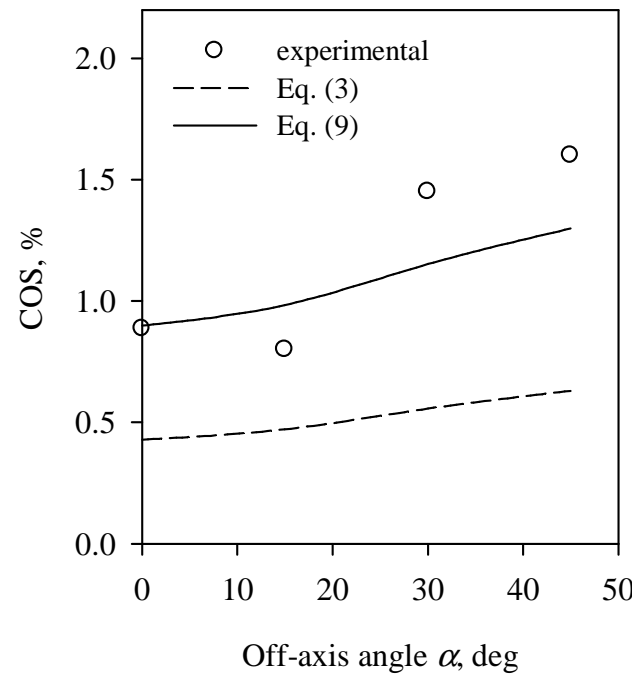

Figure 3. Crack onset strain in the inner laminae of cross-ply composite $\left[\alpha_{2} /(\alpha-\right.$ 90) $\left.{ }_{2}\right]_{\mathrm{s}}$ under uniaxial tension $(\mathrm{O})$. Crack initiation strain according to (3) is plotted by dashed line and propagation strain (9) by solid line.

\section{Conclusions}

Theoretical estimates of the strain at ply cracking onset in tension of a composite laminate comprising unidirectionally reinforced plies are derived. The estimates are based on a quadratic, in terms of transverse and shear stresses, ply strength criterion for initiation controlled cracking, and on linear, in terms of mode I and mode II energy release rates, crack growth criterion for propagation controlled cracking. The strength and toughness parameters characterizing the resistance to transverse cracking of a UD glass/epoxy composite are determined. The obtained theoretical relations and ply characteristics are used to predict the onset of cracking in a cross/ply composite under off-axis tension and the results compared to experimental data. It is shown that, in agreement with previous research concerning on-axis tension of cross-ply laminates, the appearance of cracks in relatively thin plies, subjected to combined loading within a laminate, is governed by a fracture mechanics criterion of crack propagation.

\section{References}

[1] Berthelot J-M 2003 Transverse cracking and delamination in cross-ply glass-fiber and carbonfiber reinforced plastic laminates: Static and fatigue loading Appl. Mech. Rev. 56 111-47

[2] Kashtalyan M and Soutis C 2005 Analysis of composite laminates with intra- and interlaminar damage Progr. Aerosp. Sci. 41 152-73

[3] Parvizi A, Garrett K and Bailey J 1978 Constrained cracking in glass fibre-reinforced epoxy cross-ply laminates J. Mater. Sci. 13 195-201

[4] Dvorak GJ and Laws N 1987 Analysis of progressive matrix cracking in composite laminates II. First ply failure J. Compos. Mater. 21 309-29

[5] Abe S, Kageyama K, Ohsawa I, Kanai M and Kato T 2001 Analytical prediction and experiment of transverse lamina cracking in multidirectionally reinforced symmetric laminates Proc. $7^{\text {th }}$ Japan International SAMPE Symposium and Exhibition pp 817-20

[6] Andersons J, Joffe R, Spārniņš E and Rubenis O 2009 Progressive cracking mastercurves of the transverse ply in a laminate Polym. Compos. in press (DOI 10.1002/pc.20674) 
5th International EEIGM/AMASE/FORGEMAT Conference on Advanced Materials Research IOP Publishing IOP Conf. Series: Materials Science and Engineering 5 (2009) $012018 \quad$ doi:10.1088/1757-899X/5/1/012018

[7] Boniface L, Smith PA, Bader MG and Rezaifard AH 1997 Transverse ply cracking in cross-ply CFRP laminates - initiation or propagation controlled? J. Compos. Mater. 31 1080-112

[8] Gudmundson P and Alpman J 2000 Initiation and growth criteria for transverse matrix cracks in composite laminates Compos. Sci. Technol. 60 185-95

[9] Anderson YaA, Limonov VA and Tamuzh VP 1990 Failure during axial loading of a plastic reinforced at oblique angles with organic fibers Mech. Compos. Mater. 26 182-7

[10] Crocker LE, Ogin SL, Smith PA and Hill PS 1997 Intra-laminar fracture in angle-ply laminates Compos. A 28 839-46.

[11] Andersons J, Spārniņš E and Joffe R 2008 The onset of mixed mode intralaminar cracking in a cross-ply composite laminate Mech. Compos. Mater. 44 549-56

[12] Spārniņš E, Andersons J and Varna J 2005 Applicability range of the one-parameter ply plasticity model for prediction of the nonlinear response of laminates Adv. Compos. Lett. 14 23-8

[13] Sparnins E and Andersons J 2007 Modeling the nonlinear response of composite laminates based on plasticity theory Mech. Compos. Mater. 43 203-10

[14] Tamužs V, Andersons J, Spārniņš E and Varna J 2002 Response of cross-ply composite to offaxis loading J. Compos. Mater. 36 2125-34

[15] Hashin Z and Rotem A 1973 A fatigue failure criterion for fiber reinforced materials J. Compos. Mater. 7 448-64

[16] Perevozchikov VG, Limonov VA, Protasov VD and Tamuzh VP 1988 Static and fatigue strength of unidirectional composites under the combined effect of shear stress and transverse tension-compression stresses Mech. Compos. Mater. 24 638-44

[17] Joffe R, Krasnikovs A and Varna J 2001 COD-based simulation of transverse cracking and stiffness reduction in $\left[\mathrm{S} / 90_{\mathrm{n}}\right]_{\mathrm{S}}$ laminates Compos. Sci. Technol. 61 637-56

[18] Lundmark P and Varna J 2005 Constitutive relationships for laminates with ply cracks in inplane loading Int. J. Damage Mech. 14 235-59

[19] Lundmark P and Varna J 2006 Crack face sliding effect on stiffness of laminates with ply cracks Compos. Sci. Technol. 66 1444-54 